\title{
Splenic trauma: endovascular treatment approach
}

\author{
Maxwell Cretcher, Catherine E. P. Panick, Alexander Boscanin, Khashayar Farsad
}

Department of Interventional Radiology, Dotter Interventional Institute, Oregon Health and Science University, Portland, OR, USA

Contributions: (I) Conception and design: All authors; (II) Administrative support: All authors; (III) Provision of study materials or patients: All authors; (IV) Collection and assembly of data: All authors; (V) Data analysis and interpretation: All authors; (VI) Manuscript writing: All authors; (VII) Final approval of manuscript: All authors.

Correspondence to: Khashayar Farsad. Dotter Department of Interventional Radiology, 3181 SW Sam Jackson Park Road, L-605, Portland, OR 97239, USA. Email: farsad@ohsu.edu.

\begin{abstract}
The spleen is a commonly injured organ in blunt abdominal trauma. Splenic preservation, however, is important for immune function and prevention of overwhelming infection from encapsulated organisms. Splenic artery embolization (SAE) for high-grade splenic injury has, therefore, increasingly become an important component of non-operative management (NOM). SAE decreases the blood pressure to the spleen to allow healing, but preserves splenic perfusion via robust collateral pathways. SAE can be performed proximally in the main splenic artery, more distally in specific injured branches, or a combination of both proximal and distal embolization. No definitive evidence from available data supports benefits of one strategy over the other. Particles, coils and vascular plugs are the major embolic agents used. Incorporation of SAE in the management of blunt splenic trauma has significantly improved success rates of NOM and spleen salvage. Failure rates generally increase with higher injury severity grades; however, current management results in overall spleen salvage rates of over $85 \%$. Complication rates are low, and primarily consist of rebleeding, parenchymal infarction or abscess. Splenic immune function is felt to be preserved after embolization with no guidelines for prophylactic vaccination against encapsulated bacteria; however, a complete understanding of post-embolization immune changes remains an area in need of further investigation. This review describes the history of SAE from its inception to its current role and indications in the management of splenic trauma. The endovascular approach, technical details, and outcomes are described with relevant examples. SAE is has become an important part of a multidisciplinary strategy for management of complex trauma patients.
\end{abstract}

Keywords: Splenic trauma; blunt abdominal trauma; endovascular; embolization; interventional radiology

Submitted Jun 02, 2020. Accepted for publication Sep 21, 2020.

doi: $10.21037 / \mathrm{atm}-20-4381$

View this article at: http://dx.doi.org/10.21037/atm-20-4381

\section{Introduction}

\section{Origins of splenic endovascular intervention for trauma}

The spleen is one of the most commonly injured organs in blunt abdominal trauma (1-3). As such, efficient and effective management of traumatic splenic injury is imperative in decreasing morbidity and mortality. Historically, the most common treatment of traumatic splenic injury was operative management with splenectomy. However, in the 1970s, an observed increase in infection rates from encapsulated bacteria in pediatric patients who had undergone splenectomy prompted re-evaluation of splenic injury management $(4,5)$. Pre-operative endovascular techniques using temporary balloon-occlusion and gelatin sponge embolization of the splenic artery had been performed in that era as an adjunctive procedure before splenectomy. A natural extension of this experience was implementation of splenic artery embolization (SAE) as a spleen-salvaging treatment for non-operative management (NOM) of splenic trauma. The technique was first described by Sclafani in 1981 in his report on four cases of traumatic splenic injury illustrating the use of gelatin sponge, steel 


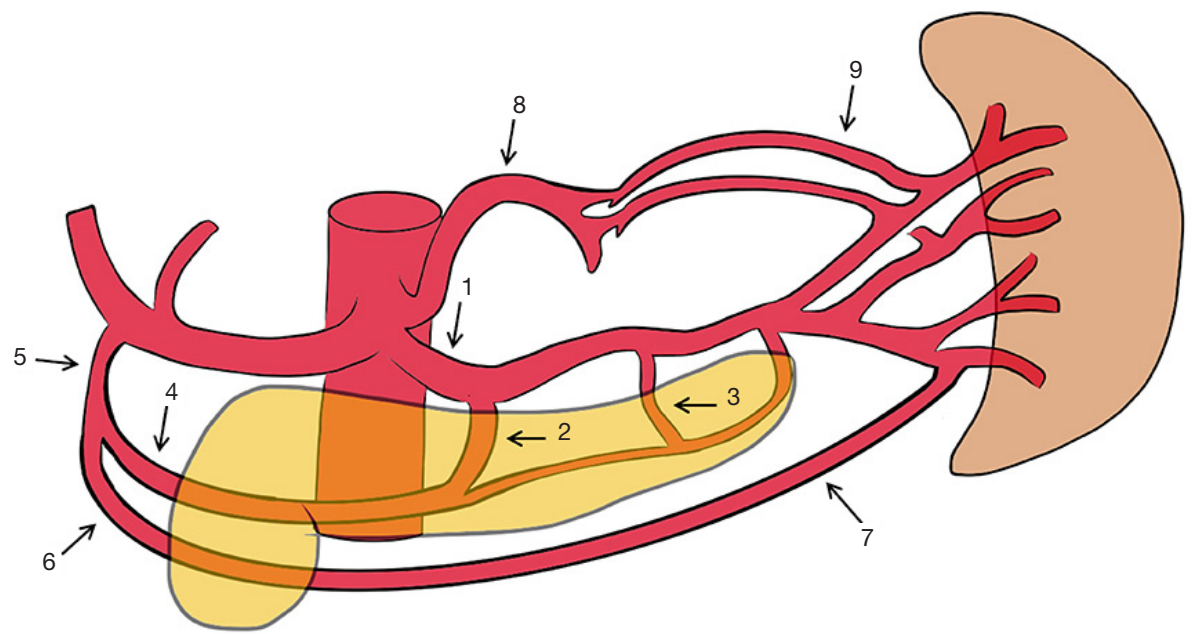

Figure 1 Schematic drawing of the splenic artery and associated collaterals. The main splenic artery [1] is a branch of the celiac artery providing direct flow to the spleen. The splenic artery gives rise to major pancreatic branches, the dorsal pancreatic artery [2] and the greater pancreatic artery or pancreatica magna [3], which form anastomoses with the transverse pancreatic artery [4] originating from the gastroduodenal artery [5]. This system is a source of collateral supply to the distal splenic artery with proximal splenic artery embolization. Additional collaterals arise from the gastroepiploic arcade: right gastroepiploic artery [6] to the left gastroepiploic artery [7], and the left gastric artery [8] to the short gastric arteries [9].

wool coils, and vasopressin infusion in the treatment of splenic trauma (6). The goal of SAE is to reduce flow in the main splenic artery to achieve hemostatic control while preserving lower pressure collateral flow to the parenchyma (Figure 1). Since that time, mounting data has continued to identify splenectomy as a risk factor for severe infection from encapsulated bacteria, known as overwhelming postsplenectomy infection (OPSI), supporting the spleen's role in infection prevention (7-11). In combination with proliferation and advancement of endovascular techniques, SAE has now become a more widely used treatment in the management of traumatic splenic injury (1,12-15).

\section{Operative vs. non-operative management of splenic trauma}

The decision to operate on the patient with blunt abdominal trauma is heavily based on initial clinical presentation. Patients who present in shock or with hemodynamic instability despite resuscitative efforts are typically triaged for emergent splenectomy (16,17). For the hemodynamically stable patient, NOM is considered the current standard of care for splenic trauma (18-20). Imaging assessment is paramount in characterizing and grading splenic injury and potentially determining management. Patients who are hemodynamically stable are typically evaluated with contrast-enhanced computed tomography (CT) of the chest, abdomen, and pelvis $(2,16,17)$. The addition of arterial phase contrast imaging has been observed to increase sensitivity of detecting pseudoaneurysms or contained vascular injuries; however, the need for routine use of arterial phase imaging has been questioned due to the number of scans obtained for blunt abdominal trauma and the relatively small percentage for which this may actually affect clinical management when identifying splenic injury (21-23). If imaging reveals a more pressing injury necessitating immediate surgical intervention (e.g., transection of the spinal cord requiring emergent decompression), treatment of a splenic injury is often delayed and further management is determined by the patient's clinical course (17).

The most widely used splenic injury grading system was developed by the American Association for the Surgery of Trauma (AAST) and includes various imaging-based criteria regarding type, size, and location of injury $(24,25)$. The grading system was recently revised in 2018 to include additional criteria concerning splenic vascular injury, such as imaging evidence of contrast extravasation (25). Currently, splenic injury of AAST grade III or higher, or evidence of active extravasation of contrast, splenic vascular injury (e.g., pseudoaneurysm), and/or large intraperitoneal 
blood volume on imaging are all potential indications to proceed with angiographic evaluation and embolization in hemodynamically stable patients (16,26-28). Indeterminate imaging findings, such as irregular or focal areas of hyperattenuation, may necessitate further clarification via conventional angiography depending on clinical findings or ongoing resuscitation needs $(2,26)$. Some debate exists regarding the reliability of $\mathrm{CT}$ in accurately characterizing splenic injury and, although limited, there is evidence showing a stronger correlation of angiographic findings with ultimate patient outcomes (29). However, catheter angiography has inherent risks and limitations, particularly in cases of major trauma or polytrauma, and contrastenhanced CT remains the diagnostic test of choice in hemodynamically stable patients who have sustained blunt abdominal trauma $(21,30)$.

\section{SAE in management of splenic trauma}

There is inconsistency in the literature regarding the classification of SAE as part of NOM, or as a distinct treatment entity $(1,18,31)$. Whether NOM includes SAE needs to be considered in assessing comparative outcomes and complication rates for splenic trauma. The decision to proceed with angiography does not necessitate proceeding with SAE. If angiography reveals active bleeding, arteriovenous fistula (AVF), pseudoaneurysm, or extensive parenchymal injury in the setting of significant hemoperitoneum, embolization is generally indicated $(16,28)$. In the absence of these positive angiographic findings, some experts advocate for empiric embolization based on initial CT findings while others feel clinical evidence of active hemorrhage (such as dropping hematocrit) should guide the decision to embolize; however, no studies have directly compared these two approaches $(26,28,32)$. A severely injured spleen that may not be actively bleeding at angiography, however, remains at high risk for delayed rupture if CT shows evidence of highgrade injury (27,33-37). The authors, therefore, advocate for a multidisciplinary approach with the trauma team that factors patient risk, findings on CT and clinical parameters on the relative merits of embolization given CT findings of a high-grade (III-V) injury.

In patients with known splenic injury, but without an imaging-based indication for angiographic evaluation (e.g., injury grades I-II), clinical course and status primarily dictate management. In this population, indications to proceed with angiography include hemodynamic lability, ongoing transfusion requirements, and evidence of delayed bleeding (e.g., abrupt drop in hematocrit) $(16,38)$. Generally, most delayed bleeding will occur within the hospital setting while patients are under observation. In one prospective study, only $1.4 \%$ of patients with blunt splenic injury managed nonoperatively required readmission for splenectomy within 180 days of discharge (39). Of these, $63.6 \%$ of readmissions for splenectomy occurred within the first seven days of discharge and almost $80 \%$ occurred within three weeks of initial injury, highlighting the relatively acute nature of splenic injury (39). Patients with blunt abdominal trauma are often highly complex and management is influenced by institutional protocol, experience of the surgical and interventional teams, and underlying patient comorbidities (28). The decision to proceed with SAE ultimately requires a thoughtful, multidisciplinary approach.

\section{Technique}

\section{Access and angiography}

Percutaneous common femoral artery access is traditionally obtained for visceral angiography and selective celiac artery catheterization using a 4- to 5-French curved catheter with or without a vascular sheath at the access site. The radial artery has additionally been described as a successful alternative access site, though it requires the use of dedicated access devices and longer catheters (Figure 2) (40). Radial access may be a good option for patients with pelvic trauma, those that require a pelvic binder, have existing femoral lines, or are obese $(40,41)$.

The starting 4- to 5-French catheter can be used to selectively catheterize the splenic artery. In the setting of celiac stenosis, a highly tortuous splenic artery, or by operator preference, a coaxial microcatheter may be helpful for selective catheterization of the splenic artery. Celiac and splenic artery angiography is performed to study the vascular anatomy, collateral splenic perfusion, and splenic parenchyma (Figure 3). Angiographic evaluation should be tailored to assess the splenic artery size, tortuosity, location of the major pancreatic artery branches, and the presence of celiac artery collaterals to the spleen, including from the left gastric artery, gastroepiploic arteries, and pancreatic artery branches (Figure 3) (42). This assessment helps to plan the embolization and reduce risk of non-target embolization or ischemia. It is important to identify major proximal pancreatic branches, particularly, the dorsal pancreatic 

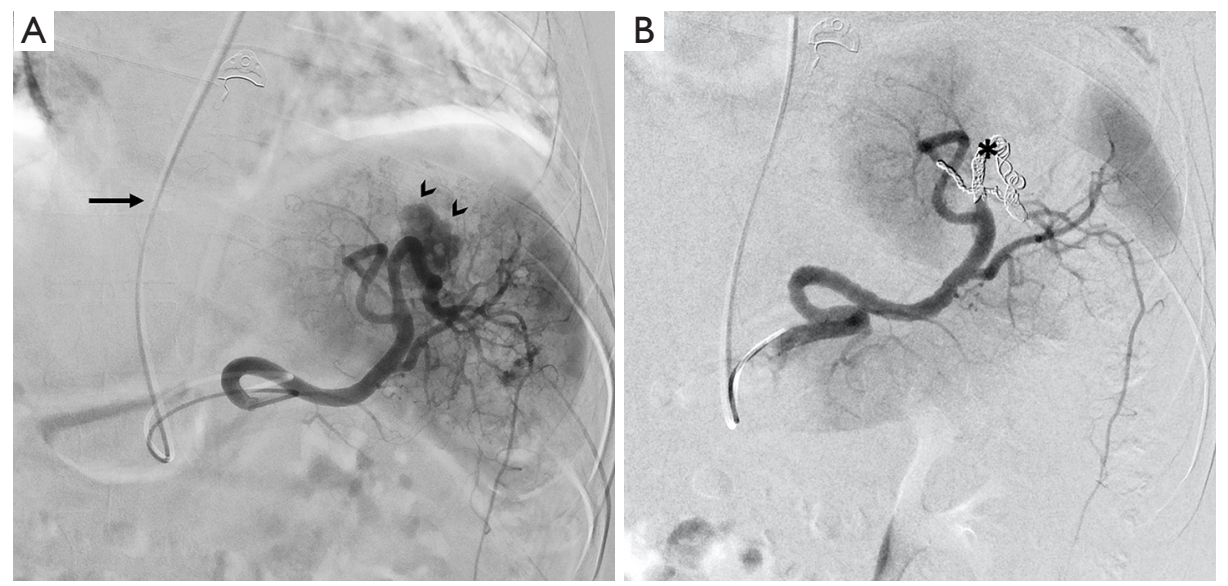

Figure 2 DSA image of the splenic artery before (A) and after (B) distal embolization with metallic coils (asterisk) demonstrates catheter access via transradial artery approach (arrows). Arrowhead denotes area of parenchymal injury with contrast extravasation (Image courtesy of Dr. Ramsey Al-Hakim).
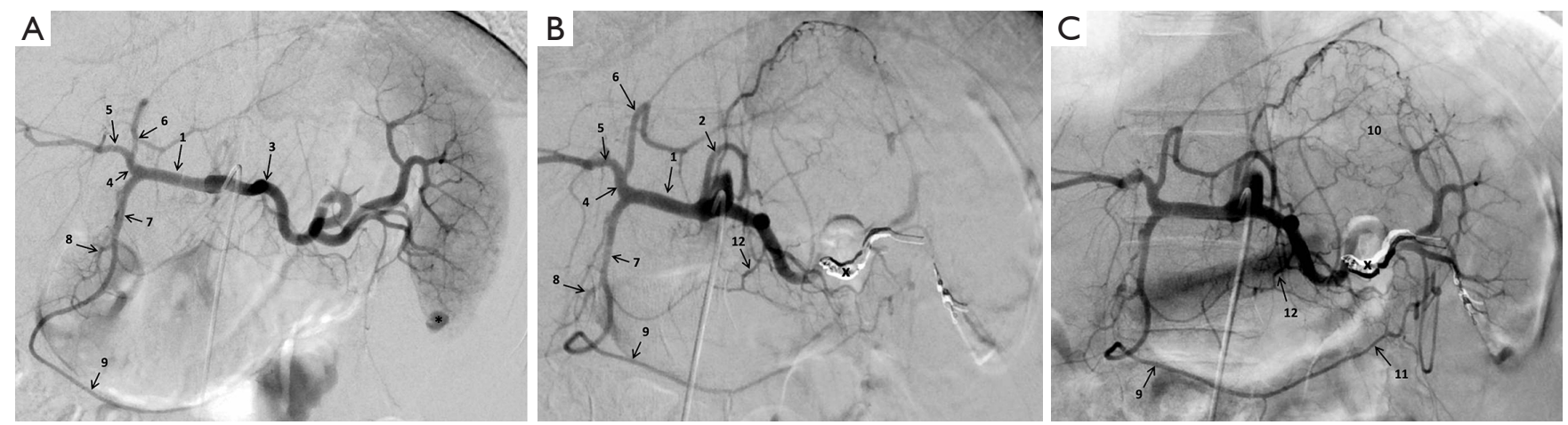

Figure 3 DSA images demonstrating active hemorrhage in the inferior splenic pole (asterisk) before (A) and after (B, C) combined distal and proximal coil embolization (X). Typical anatomy of the celiac trunk is demonstrated with trifurcation into the common hepatic artery [1], left gastric artery [2], and splenic artery [3]. The common hepatic artery gives rise to the proper hepatic artery [4], which divides into the right [5] and left hepatic arteries [6]. The gastroduodenal artery [7] branches into the pancreaticoduodenal [8] and right gastroepiploic arteries [9]. The splenic artery gives rise to the short gastric [10], left gastroepiploic [11], and dorsal pancreatic artery [12].

artery. The dorsal pancreatic artery has a variable origin, but typically arises from the proximal main splenic artery (Figures 1,3) $(42,43)$. Variant visceral or intestinal arteries that originate from the splenic artery should also be identified to avoid non-target embolization (44-46) (Figure 4).

\section{Embolization strategy}

The goal of SAE for trauma is to reduce high-pressure arterial flow to the injured site to facilitate hemostasis and decrease the risk of delayed rupture. Embolization can be performed proximally (in the main splenic artery)
(Figures 5,6), distally (in peripheral arterial branches within the splenic parenchyma) (Figure 7), or as a combination of both (Figure 8). The ideal location of embolization has been the subject of prior retrospective study without conclusive demonstration of a superior method, as all methods have been observed with similar clinical success rates $(47,48)$. Theoretical advantages of proximal embolization may include less procedural and fluoroscopy times, with the risk of limited options to access the artery for repeat embolization if needed. Theoretical advantages of distal embolization include maximal preservation of splenic tissue and the potential for reintervention if needed, with risks 

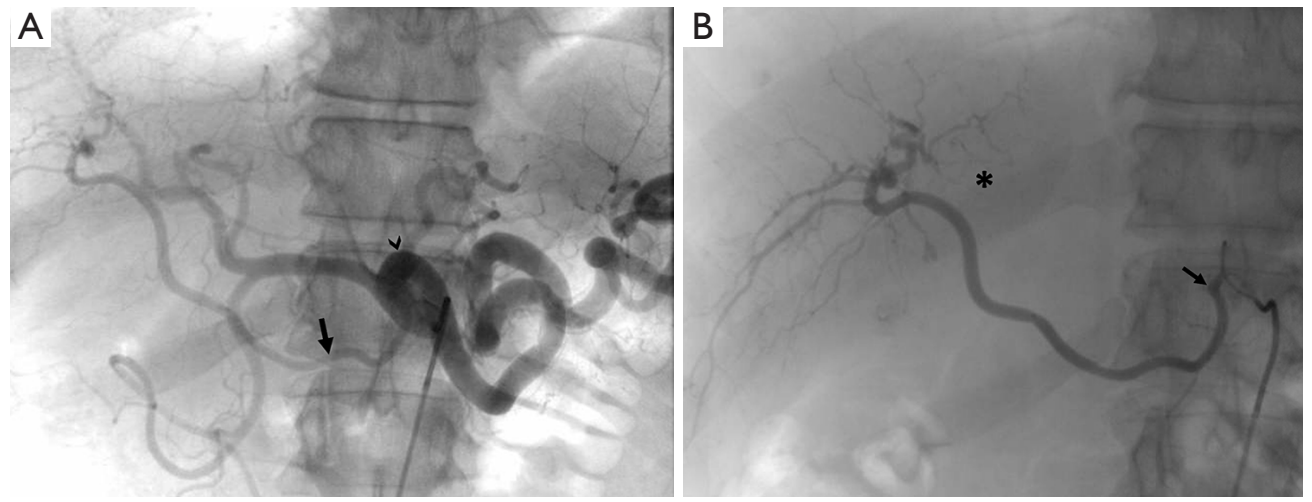

Figure 4 DSA image of the celiac trunk (A) demonstrating a replaced right hepatic artery (arrow) off of the proximal splenic artery (arrowhead). Selective catheterization of the replaced right hepatic artery (B) shows distal parenchymal enhancement of the liver (asterisk).
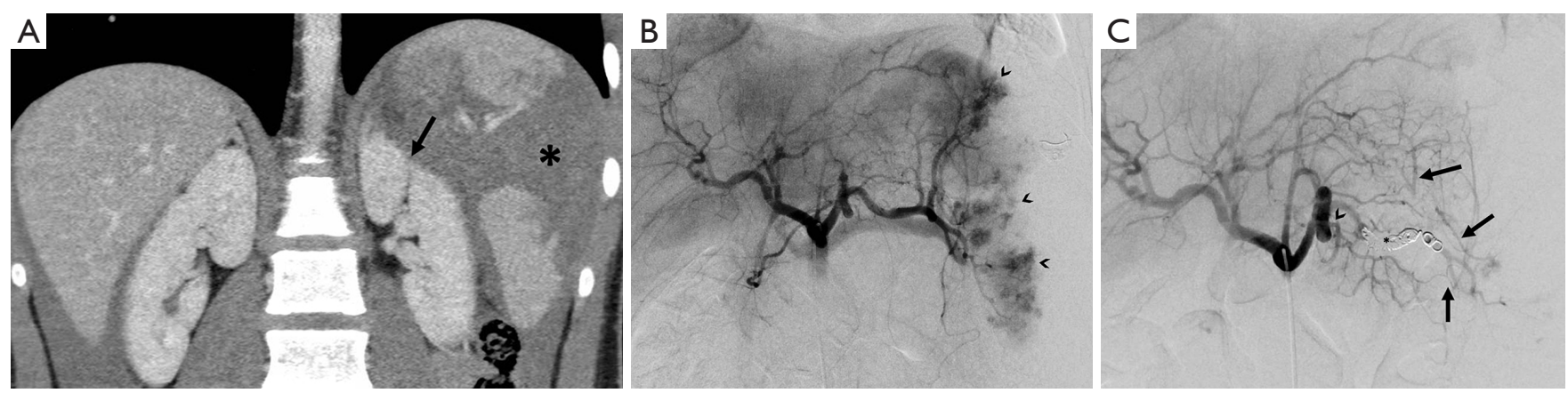

Figure 5 Coronal contrast-enhanced CT image (A) showing splenic rupture with intraparenchymal hematoma (asterisk) causing mass effect on the adjacent left kidney (arrow) in a patient with blunt abdominal trauma; (B) subsequent DSA image of the celiac trunk revealed multifocal hemorrhage (arrowheads); (C) post-embolization DSA image demonstrated hemostatic control with proximal coil embolization (asterisk). Note reconstituted perfusion to the spleen via pancreatic and short gastric artery collaterals (arrows). Arrowhead indicates the dorsal pancreatic artery.

including ongoing bleeding from missed splenic injuries or creation of peripheral splenic infarcts.

The principle behind proximal embolization is a reduction in main splenic artery perfusion pressure, allowing clot formation and hemostasis, while preserving lower pressure collateral flow to the spleen and, thus, splenic function (49-51). To illustrate the effect of SAE on distal perfusion pressure, blood pressure in the splenic artery was measured before and after transient proximal balloon occlusion in seven patients with traumatic splenic injuries (Figure 9) (50). The average reduction in systolic blood pressure was $75 \mathrm{mmHg}$ (61\% average reduction). It was noted that in one patient with celiac stenosis and robust vascular collaterals to the distal splenic artery, the reduction only measured $40 \mathrm{mmHg}(28 \%)$. Excluding this patient from the group, the average systolic blood pressure reduction was $81 \mathrm{mmHg}$ (67\%) (50). While demonstrating the association between perfusion pressure and SAE, this study also suggests potential limitations for proximal embolization in select patients with underlying celiac axis stenosis and/or robust collateral flow to the spleen.

For proximal embolization, it is important to deploy coils or plugs distal to major proximal pancreatic branches, such as the dorsal pancreatic artery $(43,49)$. A location within the mid-distal main splenic artery beyond the dorsal pancreatic artery is thought to be safe in order to reduce the risk of non-target embolization of the pancreas and resulting pancreatitis or pancreatic necrosis (52-55). Embolization between the dorsal pancreatic artery and great pancreatic artery, or pancreatica magna, preserves 

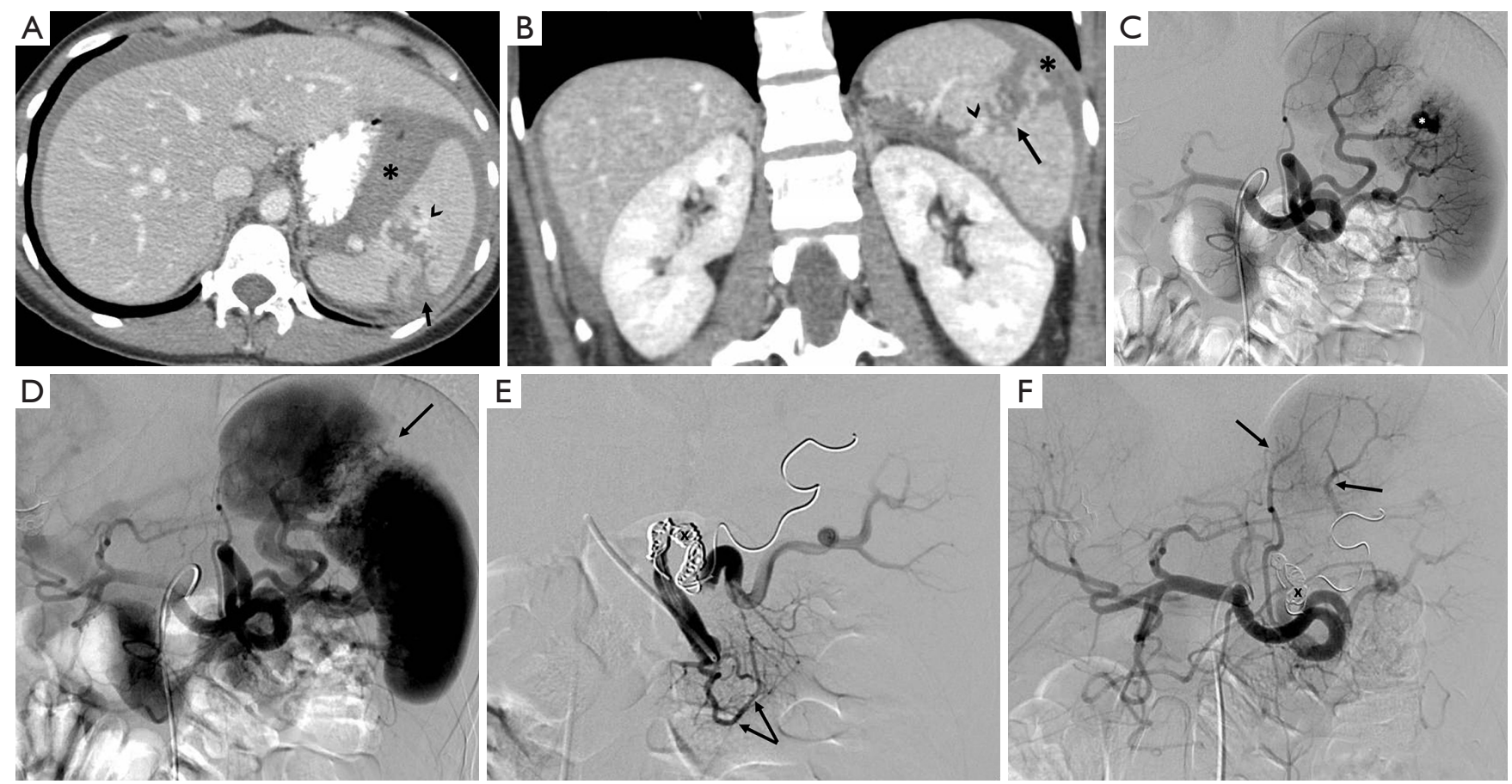

Figure 6 Contrast-enhanced axial (A) and coronal (B) CT images demonstrate a laceration through the mid-spleen (arrow) with intraparenchymal hemorrhage (arrowhead) and surrounding hematoma (asterisk). Subsequent angiographic evaluation in arterial (C) and parenchymal (D) phases confirmed parenchymal hemorrhage (asterisk) and splenic laceration (arrow). Post-embolization DSA images of the splenic artery (E) and celiac trunk (F) demonstrate significantly decreased flow after proximal splenic artery embolization with metallic coils (X). Note the preserved distal flow to the spleen via the dorsal pancreatic artery to the greater pancreatic artery in (E, arrows), and via the short gastric arteries in (F, arrows).

pancreatic supply while maintaining a collateral pathway to the spleen. Compared to distal embolization, proximal embolization has been observed with fewer complications such as rebleeding, infarction, cyst and abscess formation, as well as reduced rates of contrast induced nephropathy (47).

Distal SAE has additionally been demonstrated to be effective for focal lesions (56-59) (Figures 7,8). A co-axial microcatheter is advanced into the distal splenic arteries to the site of injury for selective embolization. Small pseudoaneurysms of distal splenic artery branches may be effectively treated with embolization of the feeding branch or the proximal main splenic artery. In the setting of a pseudoaneurysm involving the main splenic artery or a large branch artery, embolization across the site of injury can prevent retrograde perfusion of the injury site from collaterals (60-63). A combination of distal and proximal embolization may be effectively utilized to address the primary site of extravasation, but also to reduce overall splenic artery pressure to minimize risk of delayed rupture (64) (Figure 8).

\section{Embolization materials}

SAE has been performed using a variety of embolic agents. The most commonly used materials are metallic coils, vascular plugs, and gelatin sponge. Glue and polymer particulate embolic agents are thought to increase the risk for splenic infarction by causing embolization at the parenchymal level, and are primarily reserved for splenic reduction, as for hypersplenism $(16,65)$. Coils and injected gelatin sponge have been observed to have similar clinical success rates, with possibly higher complication rates observed with gelatin sponge (47).

Coils come in a variety of configurations; larger coils compatible with catheters having an inner diameter (ID) of 0.038 " -0.035 ," with available diameters generally from 3 to $20 \mathrm{~mm}$, and micro-coils compatible with microcatheters with an ID of $0.018 "-0.025 "$, with available diameters from 1 to 

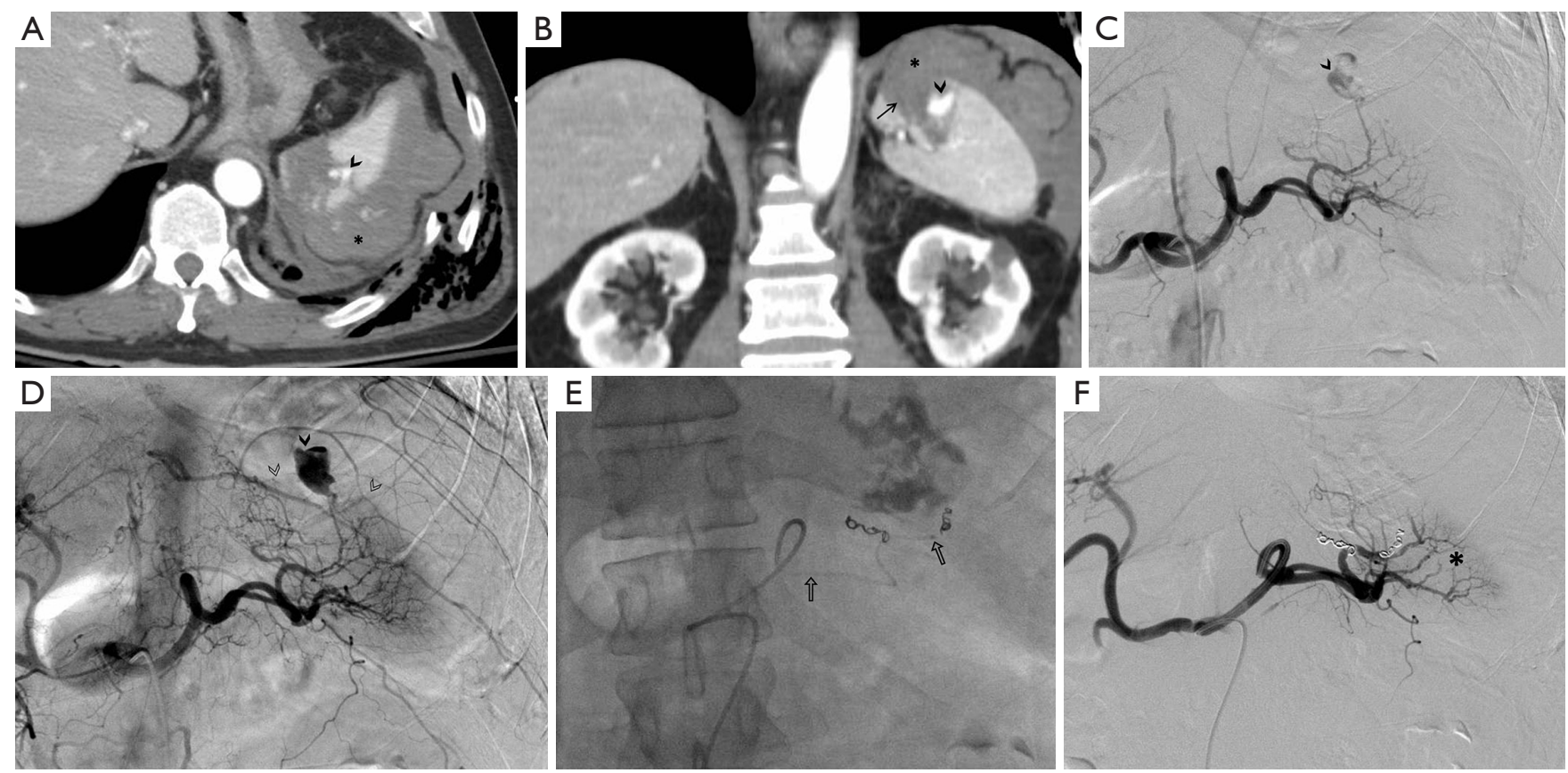

Figure 7 Contrast-enhanced axial (A) and coronal (B) CT images demonstrate a splenic laceration (arrow) and subcapsular hematoma (asterisk) with a focus of active extravasation (arrowhead). Subsequent angiographic evaluation in arterial (C) and parenchymal (D) phases confirmed active hemorrhage (arrowhead) beyond the parenchymal borders (open arrowheads) into the subcapsular space. Fluoroscopic spot image of distal splenic artery embolization with metallic coils (E) via microcatheter system (open arrows). Post-embolization DSA image of the celiac trunk (F) shows achievement of hemostasis with preservation of perfusion to the inferior splenic parenchyma (asterisk).

$32 \mathrm{~mm}$. Multiple coils are typically needed to achieve crosssectional vascular occlusion and hemostasis. Additionally, coil migration is a known risk and can be a source of complications $(66,67)$. Coils may be oversized by $20-25 \%$ of the target vessel diameter, particularly if the arteries are vasoconstricted in the setting of hemodynamic shock or vasopressor use (68). Detachable or pushable coils can be used at the discretion of the operator. Detachable coils offer such advantages as increased control of coil positioning, coil stability and packing density, but typically at a substantially greater cost compared with pushable coils (68-70).

The use of vascular plugs, such as the AMPLATZER vascular plug (AVP) (St. Jude Medical, Inc., St. Paul, Minnesota, IL, USA), can provide cross-sectional vascular occlusion with a single device (71-76) (Figure 10). With these devices, the target site must be a relatively straight vessel segment, and oversizing by $30-50 \%$ of the target vessel diameter is recommended (73). A non-tapered 4-French sheath or a 5 -French guide catheter (ID 0.056 ") is required for AVP and AVP 2 delivery (device diameters of 3-8 $\mathrm{mm}$ ). Larger diameter AVP and AVP 2 devices are available with maximal diameters up to 16 and $22 \mathrm{~mm}$, respectively. However, as a result, the delivery catheter size and ID should be matched to the device specifications per the manufacturer recommendations. This presents a potential delivery system limitation in the setting of celiac stenosis, or in highly tortuous splenic arteries. The AVP 4 device can be delivered via a non-tapered 0.038 " ID diagnostic catheter with adequate wall strength. The maximal diameter of the device is $8 \mathrm{~mm}$, making it suitable for arteries no greater than $5-6 \mathrm{~mm}$ in diameter $(72,73)$.

The IMPEDE ${ }^{\circledR}$ Embolization Plug (Shape Memory Medical Inc., Santa Clara, CA, USA) represents another device that could be potentially used for rapid occlusion of the splenic artery. The device features a shape memory polymer plug in combination with an anchor coil. The plug is designed to promote rapid conversion and organization of thrombus. Device diameters range from 6-12 $\mathrm{mm}$ and require a catheter ID range from $0.038-0.070$ ". While the company has noted use of this device in splenic trauma, no report of this device in the setting of SAE for trauma has been published to date (77). 

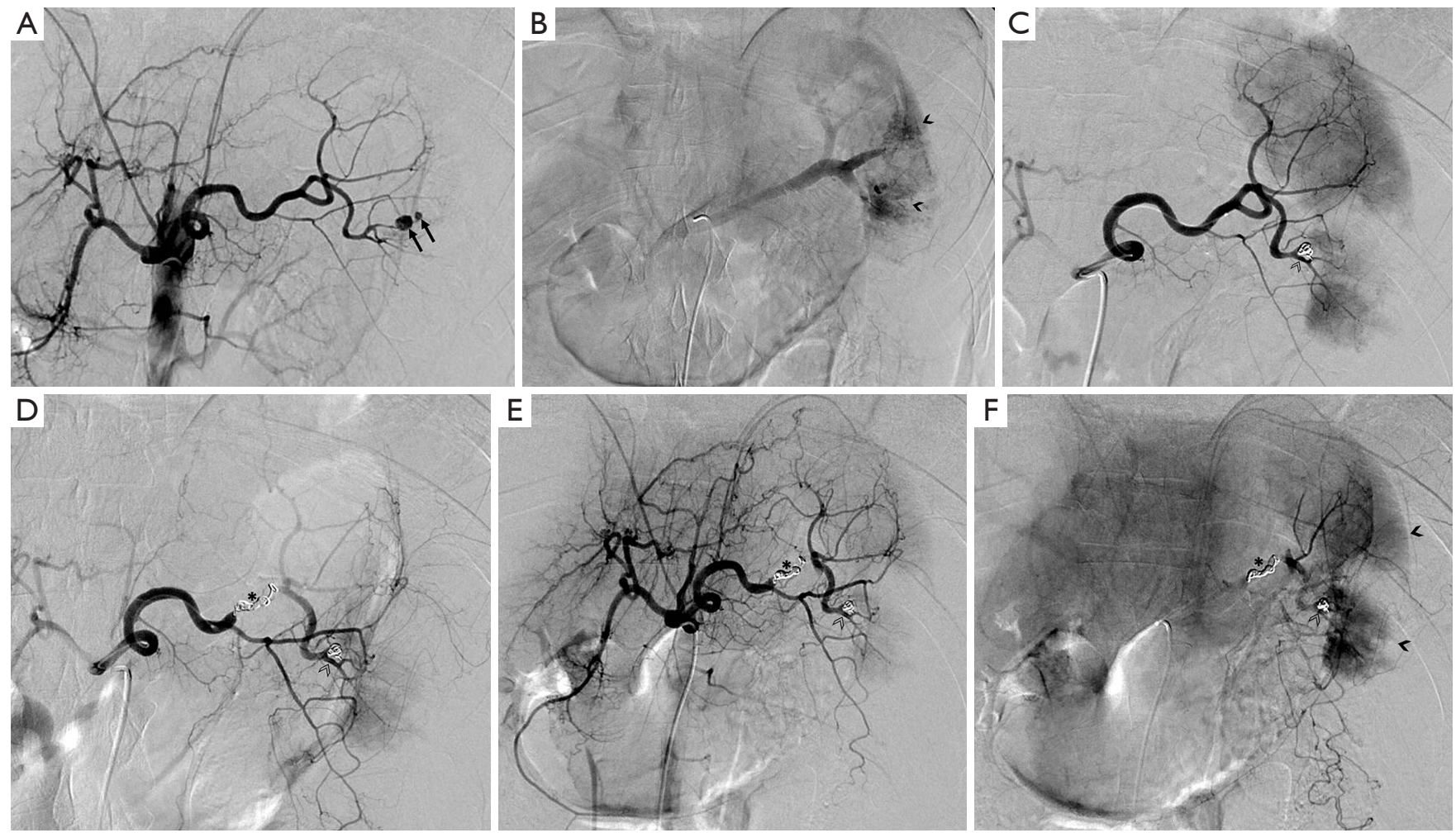

Figure 8 DSA image of the celiac artery branches (A) demonstrates inferior splenic artery pseudoaneurysms (arrows). Selective catheterization DSA image of the splenic artery (B) demonstrates multifocal parenchymal injury (arrowheads). Pseudoaneurysm was treated with distal coil embolization (C, open arrowhead) and decreased flow for hemostatic control of multifocal hemorrhage was achieved with proximal embolization (D, asterisk). Postprocedural DSA images in arterial (E) and parenchymal (F) phases demonstrate embolized pseudoaneurysm (open arrowhead) and decreased flow to areas of prior hemorrhage (arrowheads). Note the preserved flow to the spleen via preserved collaterals.

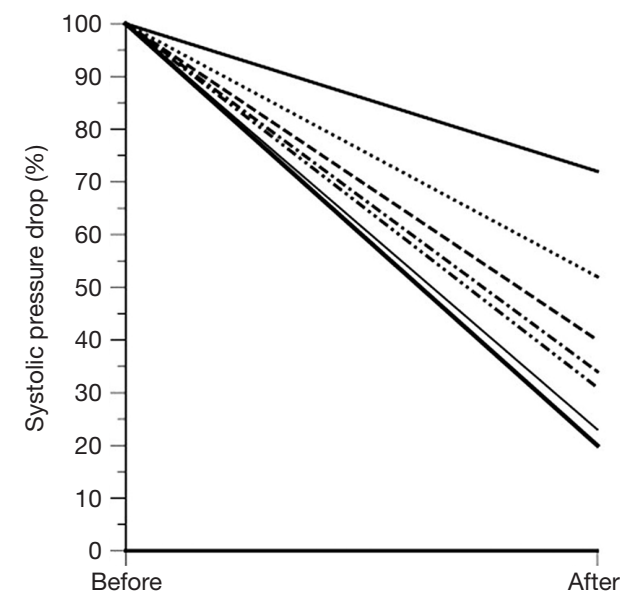

Figure 9 Systolic pressure drop (percent) in the main splenic artery before and after proximal splenic artery occlusion in seven patients. Adapted with permission from (50).
Two additional devices are currently available that are deliverable through a microcatheter, with unique advantages for use in the setting of distal embolization or in tortuous main splenic arteries. The Penumbra ${ }^{\circledR}$ occlusion device (POD ${ }^{\circledR}$, Penumbra Inc., Alameda, California, USA), can be deployed via a microcatheter and has been shown to be effective in SAE (71). The device is designed to occlude medium sized vessels from $4-8 \mathrm{~mm}$, and consists of rigid pre-formed loops followed by a long soft coil. It is advanced through the microcatheter like a coil, and is intended to effectivvely form a plug in the target vessel. The POD requires the use of 0.025 " ID microcatheter. Another such device, the MVP' Microvascular plug (Medtronic, Minneapolis, MN, USA) consists of a nitinol cage covered by a polytetrafluoroethylene (PTFE) membrane at the proximal aspect, affording the ability to be mechanically occlusive and not entirely reliant on thrombosis (Figure 11). 

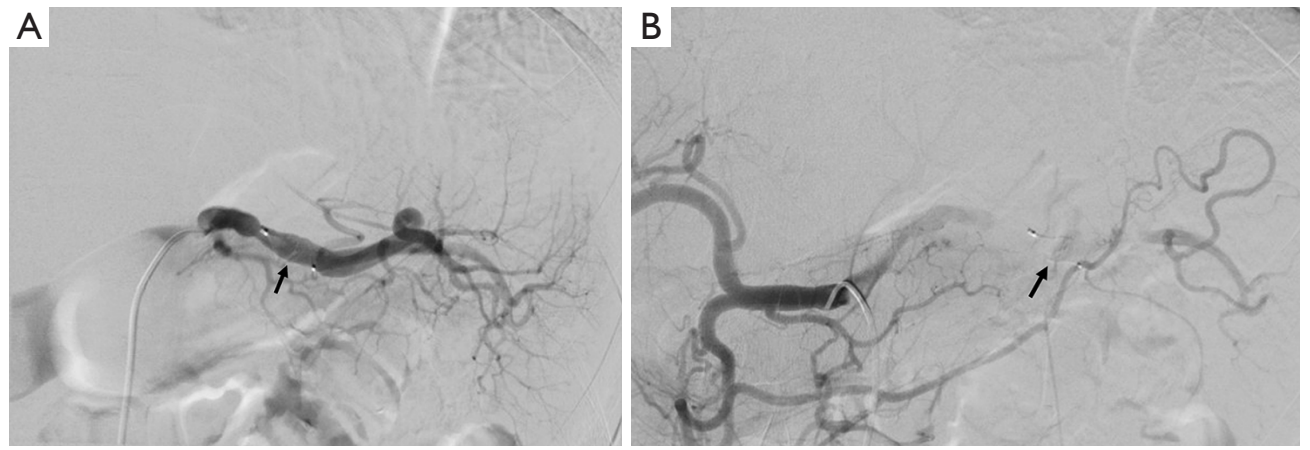

Figure 10 DSA image of the splenic artery after proximal embolization (A) with the AMPLATZER vascular plug (AVP) (St. Jude Medical, Inc., St. Paul, Minnesota, IL, USA) (arrow). Note persistent perfusion through the plug immediately after deployment. (B) Subsequent DSA image of the celiac trunk demonstrating delayed occlusion at the level of the plug (arrow) with collateral perfusion to the spleen via pancreatic branches and the gastroepiploic arcade (Image courtesy of Dr. Teodora Bochnakova).
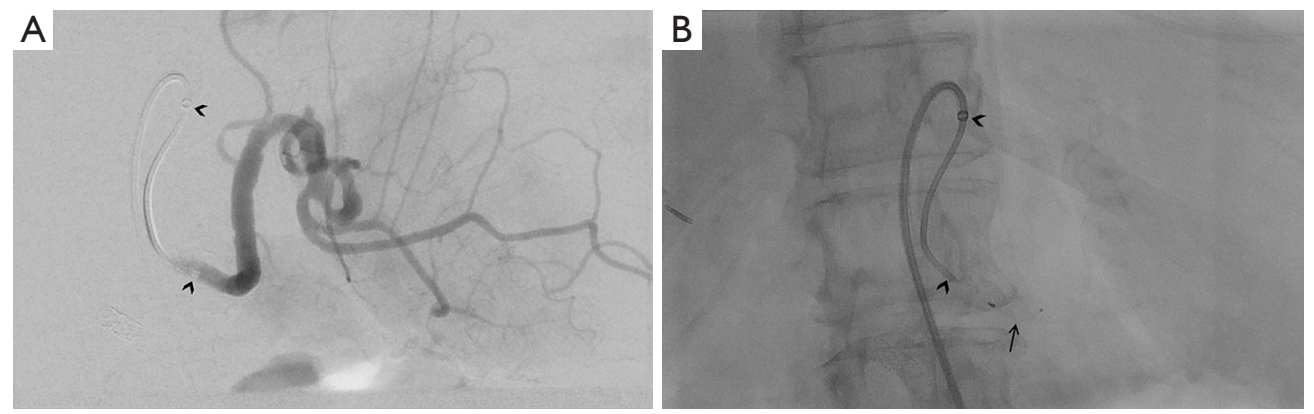

Figure 11 DSA of the splenic artery before (A) and spot fluoroscopic image after (B) proximal embolization with MVPTM Microvascular plug (Medtronic, Minneapolis, MN, USA) (arrow) deployed through a 5-Fr catheter coaxially advanced through a sheath (arrowheads) (Image courtesy of Dr. Masahiro Horikawa).

The MVP comes in four models with nominal diameters of $3,5,7$, and $9 \mathrm{~mm}$, and can be used in vessel diameters of $1.5-3,3-5,5-7$, and $7-9 \mathrm{~mm}$, respectively. The smaller models are delivered via microcatheters with 0.021 " and 0.027 " ID, and the larger models through standard 4and 5-French catheters (78). It is important to size these devices carefully to the target vessel. Under-sizing can lead to inadequate wall apposition, and oversizing can cause pleating in the PTFE membrane due to lack of sufficient expansion of the nitinol cage resulting in channels for continued blood flow and incomplete occlusion.

\section{Outcomes}

\section{Technical and clinical success rates of SAE}

Observed technical success rates for SAE, defined as complete occlusion of the selected artery, are very high, ranging from $90-100 \%(1,79,80)$. Reports of clinical success rates, defined as adequate hemostasis and splenic salvage, have ranged from $70-100 \%$, with no difference appreciated between proximal and distal embolization techniques (1,6,16,32,47,48,66,67,81-87). A multicenter retrospective review of 140 patients with a mean AAST score of 3.5 showed an $87 \%$ overall clinical success rate, with $83 \%$ success rates for AAST grade 4 and 5 injuries (67). Notably, including SAE as part of NOM has demonstrated improved outcomes compared to observation alone for the management of AAST grade 4 and 5 injuries $(83,85)$. Haan et al. reported success rates of $83 \%$ for grade 4 and 5 injuries with SAE compared to $67 \%$ and $25 \%$, respectively, with observation alone (85). A meta-analysis and systematic review by Crichton et al. had similar findings for grade 4 and grade 5 injuries with clinical failure rates of $8-13 \%$ for 


\section{Page 10 of 16}

Table 1 Failure rate of non-operative management strategies by AAST injury grade

\begin{tabular}{lcc}
\hline $\begin{array}{l}\text { AAST injury } \\
\text { grade }\end{array}$ & $\begin{array}{c}\text { Observation } \\
\text { failure rate (\%) }\end{array}$ & $\begin{array}{c}\text { Splenic artery embolization } \\
\text { failure rate (\%) }\end{array}$ \\
\hline I & 4.30 & 16.70 \\
II & 9.10 & 4.30 \\
III & 19.90 & 17.70 \\
IV & 43.70 & 17.30 \\
V & 83.10 & 25
\end{tabular}

From (87).

Table 2 Complications of splenic artery embolization for trauma

Major complications
Hemorrhage
Abscess
Infarct
Renal impairment
Minor complications
Infarct
Coil migration
Pseudocyst
Pleural effusion
Pancreatitis
Renal impairment
Fever

From $(58,66,67,80)$.

SAE versus $43-75 \%$ for observation alone (83).

In grade 3 injuries, retrospective reviews have also demonstrated a higher success rate with SAE compared to observation alone, $92 \%$ for SAE and $80 \%$ for observation (85). However, more recent literature suggests a similar failure rate between $\mathrm{SAE}$ and observation alone for grade 3 injuries, $13-17 \%(83,87)$. Some of this heterogeneity may be related to intrinsic ambiguity about grade 3 classification. Grade 3 injuries represent an intermediate risk stage between the lower grades 1-2 that are usually successfully managed with observation alone, and the higher grades 4-5 that have consistently shown to benefit from the incorporation of SAE (Table 1). Arguably, with the current AAST grading scheme which

\section{Cretcher et al. Endovascular approach to splenic trauma}

automatically upgrades injury to grade 4 in the setting of "splenic vascular injury," e.g., contained focal extravasation or pseudoaneurysm, the true risk of grade 3 injury may be more difficult to ascertain, as lesions previously potentially classified as grade 3 would be reclassified as grade 4 in the modern era. Thus, with grade 3 injury, patientspecific factors including clinical status, hematocrit levels, hemoperitoneum, and ongoing resuscitation needs should be part of a multidisciplinary consensus strategy to guide the decision to embolize $(32,67,83-86,88)$.

\section{Complications from $S A E$}

Complications from SAE have been reported with a wide range of incidence (Table 2). Major complications range from 0 to $29 \%$ and minor complications range from $5 \%$ to $62 \%(58,66,67,79,80)$. A multi-institutional retrospective review of 140 patients showed an overall complication rate of $36 \%$ with a $20 \%$ major complication rate and $23 \%$ minor complication rate (67). No significant difference in overall complication rate has been demonstrated between proximal and distal embolization $(66,67,79,85)$. Recurrent intra-abdominal bleeding was the most common major complication and occurred in $11 \%$ of patients requiring either repeat embolization or splenectomy (67). Use of gelatin-sponge embolic material has been observed to potentially contribute to increased rebleeding rates compared to coil embolization (58). Bleeding rates may also be related to additional unrecognized and untreated injuries (67). Additionally, prominent collateral arteries and coagulopathy may contribute to bleeding after proximal embolization. Less common major complications include splenic abscess, which was observed in $4 \%$ of patients, and large infarcts which occurred in $1.4 \%$ (67). Partial splenic infarction, defined by $<25 \%$ of splenic parenchymal involvement, is the most common minor complication $(48,67,82,89)$. In a retrospective review by Haan et al., partial splenic infarction occurred in $21 \%$ of patients (67). While infarction was more commonly seen after distal SAE than proximal SAE ( $27 \%$ vs. $19 \%$ of patients), the overall number of infarctions was incompletely evaluated as not all patients had follow up imaging (67). Coil migration is an uncommon minor complication and has been reported $\sim 2 \%$ of patients $(67,85)$. Post-embolization syndrome is a recognized occurrence and typically presents with left upper quadrant pain, fever, and nausea (16,32). Many other adverse events including pleural effusion, pancreatitis, pseudocyst, pneumonia, and ARDS which have been 
reported after blunt splenic trauma have not been shown to correlate with any particular management strategy (84). Of note, gas within the splenic parenchyma after SAE is often an incidental finding and may not be infectious $(32,67,89,90)$. A retrospective review found that only 2 of $12 \mathrm{SAE}$ patients with splenic infarction and associated gas had evidence of infection (90).

\section{Infection complications and $S A E$}

Although observational studies demonstrate an overall lower risk of infectious complications compared to operative management, some authors have suggested higher infection rates after NOM with SAE compared to NOM without SAE $(7,91)$. A recent, large-scale retrospective analysis querying the Nationwide Readmissions Database showed significant incidence of early infection and readmission rates for infection (including surgical site infection, sepsis, and conglomeration of all recorded infections) following SAE compared to NOM alone (91). However, this study is limited by patient heterogeneity and greater proportions of higher-grade injury in the cohort undergoing SAE. A prospective 2012 study provided some clarity by further stratifying management into NOM, SAE, splenorrhaphy, and splenectomy (7). SAE showed lower rates of early infection (including intraabdominal abscess, wound infection, UTI, pneumonia, and sepsis) compared with both splenectomy and splenorrhaphy, supporting the use of SAE as a spleen-preserving treatment. A large retrospective study examining 2,746 patients at up to 300 Levels I and II trauma centers in the Trauma Quality Improvement Program, a robust national database endorsed by the American College of Surgeons, examined outcomes of NOM specifically for high grade (grades IVV) splenic injury (33). This study examined outcomes after 2013, when SAE and blood transfusion requirements were officially recorded in the database. The study found NOM to be equally effective for high-grade splenic injury as immediate splenectomy, with significantly lower infection rates. In addition, delayed splenectomy for failed NOM did not result in worse outcomes, but rather had a significantly lower in-hospital mortality rate. Use of SAE reduced the probability of failure of NOM in high-grade splenic injury by $63 \%$ (33). Given the variability in patient factors combined with overall limited data, thorough knowledge of indications, contraindications, and scope of interventional techniques is essential to provide the most appropriate treatment.

\section{Preservation of splenic function after $S A E$}

Preservation of immune function is an important consideration favoring SAE over splenectomy. As mentioned above, the spleen provides an immune response to encapsulated bacteria and unfamiliar antigens $(16,82,88,92)$. Several studies suggest that splenic immune function is preserved after SAE, both in pediatric patients and adults $(16,82,88,92)$. Immune function has been tested by measuring general blood counts, immunoglobulin levels, T, B, and NK cells, Howell-Jolly bodies, as well as antibody response to the PPV-23 vaccine after SAE $(82,88,92)$. There is some evidence to suggest routine staining for Howell-Jolly bodies may not be sufficiently sensitive to predict hyposplenism (93). A functional imaging technique to assess splenic function includes Tc-99m tagged heat-damaged autologous erythrocytes for nuclear scintigraphy, and remains the current gold-standard for splenic function (93).

A systematic review of splenic function after embolization concluded that splenic function is preserved, with no observed case of OPSI (94). Malhotra et al. further validated this conclusion by showing that a specific subtype of CD4+ T cells was preserved after SAE, similar to that seen in healthy patients (95). Moreover, preserved immune function has been demonstrated at long term follow up (92). A review of 11 patients under the age of 17 who had SAE for trauma showed no difference in immune function between the SAE group and an age/gender matched control group at an average of 4.6 years; immune function was determined by comparing CBC, total IG A, G, and M, IgM and $\mathrm{IgG}$ antibodies to specific pneumococcal serotypes, Howell Jolly bodies, and splenic length (92). Of note, SAE has been observed to correlate with higher rates of infection relative to NOM alone, suggesting a possibility of compromise in immune function in addition to periprocedural infection directly related to SAE (91). This infection risk and its etiology, however, remains uncertain. Some authors recommend prophylactic vaccination in cases where $>50 \%$ of the splenic parenchyma has been embolized (96); however, there are no universal consensus guidelines regarding antibiotic prophylaxis or vaccination following SAE in trauma. Nevertheless, optimal work up for splenic function after SAE remains an incompletely defined clinical parameter.

\section{Follow-up after SAE}

There is currently no consensus regarding the need for 
follow-up imaging or long-term management following SAE. The basis of post-hospitalization management and follow-up imaging revolves around the risk of delayed splenic rupture in the short term, and monitoring of splenic function in the long term. A retrospective study of 475 blunt splenic injury patients managed with either observation alone or with SAE found that $6 \%$ of patients had imaging findings of active extravasation or pseudoaneurysm on follow up CT imaging at 48 hours (97); however, the authors did not stratify the result between patients who received embolization and those who did not. While most of these findings were seen in higher grade injuries, about $20 \%$ occurred in grade 1 or grade 2 injuries (97). By contrast, a separate retrospective study in which 57 asymptomatic patients received routine postprocedure imaging between 0 and 11 days, $96.4 \%$ had no new clinically significant findings (98). The new findings noted were increased abdominal fluid in two patients, both of whom were managed with observation (98). Of 18 patients who received follow up imaging based on clinical symptoms, 8 had significant findings and 4 had NOM failure (98). Neither of these studies stratified patients who received SAE from those managed with observation alone. Follow-up CT at 48 hours may be useful for early identification of splenic pseudoaneurysm and active extravasation; however, further routine imaging may not be of clinical value unless based on the presence of new or worsening symptoms.

In the Splenic Injury Outcomes Trial, a multiinstitutional study by the AAST, patients were followed at 30,90 , and 180 days. The risk of splenectomy was only $0.3 \%$ after 180 days (99). A separate review of 26 patients who received follow-up at a mean time of 26 months after embolization did not show any interim medical consultations, hospitalizations, procedures related to rebleeding, or other embolization-related complication $(32,82)$. The data on this issue is mixed, however, as a large retrospective study using the Nationwide Readmissions Database indeed found higher rates of readmission for infectious complications after SAE at both 30 days and up to one year after initial hospitalization compared to NOM alone (91). Nevertheless, the risk of delayed rupture after SAE is therefore likely low and long-term follow-up specifically for this event may not be necessary.

\section{Conclusions}

$\mathrm{SAE}$ is an effective management strategy for blunt splenic trauma in hemodynamically stable patients with AAST grade III-V injuries and those with findings of contrast extravasation, vascular abnormality (e.g., pseudoaneurysm), and hemoperitoneum. Diagnosis is based on the AAST grading system using imaging criteria on initial contrast enhanced CT. SAE may be performed with either a proximal, distal, or combined proximal and distal approach to reduce splenic arterial inflow and perfusion pressure, facilitate hemostasis, and reduce the risk of delayed splenic rupture. Each of these techniques have similar technical and clinical success rates and comparable complication rates. Metallic coils are commonly used for embolization; however, vascular plugs and other embolic devices may be considered in the appropriate clinical settings. Splenic immune function seems to be preserved after SAE; however, whether there remain higher post-SAE infection risks and the etiologies of these infections remain uncertain.

\section{Acknowledgments}

Funding: None.

\section{Footnote}

Provenance and Peer Review: This article was commissioned by the Guest Editor (Keith Bertram Quencer) for the series "Endovascular Interventions in Trauma" published in Annals of Translational Medicine. The article has undergone external peer review.

Conflicts of Interest: All authors have completed the ICMJE uniform disclosure form (available at http://dx.doi. org/10.21037/atm-20-4381). The series "Endovascular interventions in trauma" was commissioned by the editorial office without any funding or sponsorship. Dr. KF reports other from Auxetics, Inc., personal fees from Cook Medical, personal fees from BTG, personal fees from Neuwave, grants and personal fees from Guerbet, LLC, personal fees from Genentech, personal fees from Dova Pharmaceuticals, outside the submitted work; In addition, Dr. KF has a patent "use of specific stent class for the management of venous stenosis" licensed to Auxetics, Inc. The authors have no other conflicts of interest to declare.

Ethical Statement: The authors are accountable for all aspects of the work in ensuring that questions related to the accuracy or integrity of any part of the work are 
appropriately investigated and resolved.

Open Access Statement: This is an Open Access article distributed in accordance with the Creative Commons Attribution-NonCommercial-NoDerivs 4.0 International License (CC BY-NC-ND 4.0), which permits the noncommercial replication and distribution of the article with the strict proviso that no changes or edits are made and the original work is properly cited (including links to both the formal publication through the relevant DOI and the license). See: https://creativecommons.org/licenses/by-nc-nd/4.0/.

\section{References}

1. Cinquantini F, Simonini E, Di Saverio S, et al. Nonsurgical Management of Blunt Splenic Trauma: A Comparative Analysis of Non-operative Management and Splenic Artery Embolization-Experience from a European Trauma Center. Cardiovasc Intervent Radiol 2018;41:1324-32.

2. Dreizin D, Munera F. Blunt polytrauma: evaluation with 64-section whole-body CT angiography. Radiographics 2012;32:609-31.

3. Stein DM, Scalea TM. Nonoperative management of spleen and liver injuries. J Intensive Care Med 2006;21:296-304.

4. Singer DB. Postsplenectomy sepsis. Perspect Pediatr Pathol 1973;1:285-311.

5. King H, Shumacker HB Jr. Splenic studies. I. Susceptibility to infection after splenectomy performed in infancy. Ann Surg 1952;136:239-42.

6. Sclafani SJ. The role of angiographic hemostasis in salvage of the injured spleen. Radiology 1981;141:645-50.

7. Demetriades D, Scalea TM, Degiannis E, et al. Blunt splenic trauma: splenectomy increases early infectious complications: a prospective multicenter study. J Trauma Acute Care Surg 2012;72:229-34.

8. Cullingford GL, Watkins DN, Watts AD, et al. Severe late postsplenectomy infection. Br J Surg 1991;78:716-21.

9. Schwartz PE, Sterioff S, Mucha P, et al. Postsplenectomy sepsis and mortality in adults. JAMA 1982;248:2279-83.

10. Kyaw MH, Holmes EM, Toolis F, et al. Evaluation of severe infection and survival after splenectomy. Am J Med 2006;119:276.e1-7.

11. Tahir F, Ahmed J, Malik F. Post-splenectomy Sepsis: A Review of the Literature. Cureus 2020;12:e6898.

12. Freeman C, Moran V, Fang A, et al. Nonoperative Management of Blunt Splenic Trauma: Outcomes of
Gelfoam Embolization of the Splenic Artery. J Emerg Trauma Shock 2018;11:293-7.

13. Gaarder C, Dormagen JB, Eken T, et al. Nonoperative management of splenic injuries: improved results with angioembolization. J Trauma 2006;61:192-8.

14. Rajani RR, Claridge JA, Yowler CJ, et al. Improved outcome of adult blunt splenic injury: a cohort analysis. Surgery 2006;140:625-31; discussion 631-2.

15. Sabe AA, Claridge JA, Rosenblum DI, et al. The effects of splenic artery embolization on nonoperative management of blunt splenic injury: a 16-year experience. J Trauma 2009;67:565-72; discussion 571-2.

16. Ahuja C, Farsad K, Chadha M. An Overview of Splenic Embolization. AJR Am J Roentgenol 2015;205:720-5.

17. Girard E, Abba J, Cristiano N, et al. Management of splenic and pancreatic trauma. J Visc Surg 2016;153:45-60.

18. Stassen NA, Bhullar I, Cheng JD, et al. Selective nonoperative management of blunt splenic injury: an Eastern Association for the Surgery of Trauma practice management guideline. J Trauma Acute Care Surg 2012;73:S294-300.

19. Patil MS, Goodin SZ, Findeiss LK. Update: Splenic Artery Embolization in Blunt Abdominal Trauma. Semin Intervent Radiol 2020;37:97-102.

20. Zarzaur BL, Dunn JA, Leininger B, et al. Natural history of splenic vascular abnormalities after blunt injury: A Western Trauma Association multicenter trial. J Trauma Acute Care Surg 2017;83:999-1005.

21. Corwin MT, Fananapazir G, Lamba R, et al. Arterial phase CT for the detection of splenic injuries in blunt trauma: would it improve clinical outcomes? Clin Imaging 2016;40:212-6.

22. LeBedis CA, Anderson SW, Mercier G, et al. The utility of $\mathrm{CT}$ for predicting bile leaks in hepatic trauma. Emerg Radiol 2015;22:101-7.

23. Uyeda JW, LeBedis CA, Penn DR, et al. Active hemorrhage and vascular injuries in splenic trauma: utility of the arterial phase in multidetector CT. Radiology 2014;270:99-106.

24. Moore EE, Cogbill TH, Jurkovich GJ, et al. Organ injury scaling: spleen and liver (1994 revision). J Trauma 1995;38:323-4.

25. Kozar RA, Crandall M, Shanmuganathan K, et al. Organ injury scaling 2018 update: Spleen, liver, and kidney. J Trauma Acute Care Surg 2018;85:1119-22.

26. Haan J, Scott J, Boyd-Kranis RL, et al. Admission angiography for blunt splenic injury: advantages and pitfalls. J Trauma 2001;51:1161-5. 
27. Becker CD, Mentha G, Terrier F. Blunt abdominal trauma in adults: role of CT in the diagnosis and management of visceral injuries. Part 1: liver and spleen. Eur Radiol 1998;8:553-62.

28. Imbrogno BF, Ray CE. Splenic artery embolization in blunt trauma. Semin Intervent Radiol 2012;29:147-9.

29. Shanmuganathan K, Mirvis SE, Boyd-Kranis R, et al. Nonsurgical management of blunt splenic injury: use of CT criteria to select patients for splenic arteriography and potential endovascular therapy. Radiology 2000;217:75-82.

30. American College of R. ACR Appropriateness Criteria: Major Blunt Trauma2019.

31. Peitzman AB, Harbrecht BG, Rivera L, et al. Failure of observation of blunt splenic injury in adults: variability in practice and adverse consequences. J Am Coll Surg 2005;201:179-87.

32. Bessoud B, Denys A, Calmes JM, et al. Nonoperative management of traumatic splenic injuries: is there a role for proximal splenic artery embolization? AJR Am J Roentgenol 2006;186:779-85.

33. Scarborough JE, Ingraham AM, Liepert AE, et al. Nonoperative Management Is as Effective as Immediate Splenectomy for Adult Patients with High-Grade Blunt Splenic Injury. J Am Coll Surg 2016;223:249-58.

34. Kluger Y, Paul DB, Raves JJ, et al. Delayed rupture of the spleen--myths, facts, and their importance: case reports and literature review. J Trauma 1994;36:568-71.

35. Pappas D, Mirvis SE, Crepps JT. Splenic trauma: falsenegative CT diagnosis in cases of delayed rupture. AJR Am J Roentgenol 1987;149:727-8.

36. Weinberg JA, Magnotti LJ, Croce MA, et al. The utility of serial computed tomography imaging of blunt splenic injury: still worth a second look? J Trauma 2007;62:11437; discussion 1147-8.

37. Furlan A, Tublin ME, Rees MA, et al. Delayed splenic vascular injury after nonoperative management of blunt splenic trauma. J Surg Res 2017;211:87-94.

38. Kandarpa K, Machan L, Durham JD. Trauma Management. In: Shaw R, editor. 5 ed. Wolters Kluwer, 2016:194-5.

39. Zarzaur BL, Vashi S, Magnotti LJ, et al. The real risk of splenectomy after discharge home following nonoperative management of blunt splenic injury. J Trauma 2009;66:1531-6; discussion 1536-8.

40. Adnan SM, Romagnoli AN, Martinson JR, et al. A Comparison of Transradial and Transfemoral Access for Splenic Angio-Embolisation in Trauma: A Single Centre Experience. Eur J Vasc Endovasc Surg 2020;59:472-9.
41. Adnan SM, Wasicek PJ, Crawford A, et al. Endovascular control of pelvic hemorrhage: Concomitant use of resuscitative endovascular balloon occlusion of the aorta and endovascular intervention. J Trauma Acute Care Surg 2019;86:155-9.

42. Uflacker AG, Marcelo. Uflacker's Atlas of Vascular Anatomy: An Angiographic Approach. 3rd Ed. ed. Lippincott Williams \& Wilkins (LWW), 2020.

43. Madoff DC, Denys A, Wallace MJ, et al. Splenic arterial interventions: anatomy, indications, technical considerations, and potential complications. Radiographics 2005;25 Suppl 1:S191-211.

44. Al Zahrani Y, AlMat'hami A, Alobaidi H, et al. Accessory Right Hepatic Artery Arising from Splenic Artery Supplying Hepatocellular Carcinoma Identified by Computed Tomography Scan and Conventional Angiography: A Rare Anatomic Variant. Ann Vasc Surg 2017;38:316.e1-316.e5.

45. Fiorello B, Corsetti R. Splenic Artery Originating from the Superior Mesenteric Artery: An Unusual but Important Anatomic Variant. Ochsner J 2015;15:476-8.

46. Slaba S, Assaf S. Aberrant gastroduodenal artery with splenic origin. Surg Radiol Anat 2018;40:1437-40.

47. Rong J-J, Liu D, Liang M, et al. The impacts of different embolization techniques on splenic artery embolization for blunt splenic injury: a systematic review and meta-analysis. Mil Med Res 2017;4:17.

48. Schnüriger B, Inaba K, Konstantinidis A, et al. Outcomes of proximal versus distal splenic artery embolization after trauma: a systematic review and meta-analysis. J Trauma 2011;70:252-60.

49. Quencer KB, Smith TA. Review of proximal splenic artery embolization in blunt abdominal trauma. CVIR Endovasc 2019;2:11.

50. Requarth JA. Distal splenic artery hemodynamic changes during transient proximal splenic artery occlusion in blunt splenic injury patients: a mechanism of delayed splenic hemorrhage. J Trauma 2010;69:1423-6.

51. Requarth JA, Miller PR. The splenic artery stump pressure is affected by arterial anatomy after proximal embolotherapy in blunt splenic injury. J Trauma Acute Care Surg 2012;73:1221-4.

52. Hamers RL, Van Den Berg FG, Groeneveld AB. Acute necrotizing pancreatitis following inadvertent extensive splenic artery embolisation for trauma. Br J Radiol 2009;82:e11-4.

53. Khurana A, Abdel Khalek M, Brown J, et al. Acute necrotizing pancreatitis following splenic artery 
embolization. Trop Gastroenterol 2011;32:226-9.

54. Paul DB, Opalek JM. Proximal splenic arterial embolization may also result in pancreatic necrosis. J Trauma 2011;71:268-9.

55. Talving P, Rauk M, Vipp L, et al. Necrosis of the tail of pancreas following proximal splenic artery embolization. J Surg Case Rep 2016;2016.

56. Dasgupta N, Matsumoto AH, Arslan B, et al. Embolization therapy for traumatic splenic lacerations. Cardiovasc Intervent Radiol 2012;35:795-806.

57. Wei B, Hemmila MR, Arbabi S, et al. Angioembolization reduces operative intervention for blunt splenic injury. J Trauma 2008;64:1472-7.

58. Wu SC, Chen RJ, Yang AD, et al. Complications associated with embolization in the treatment of blunt splenic injury. World J Surg 2008;32:476-82.

59. Wu SC, Fu CY, Chen RJ, et al. Higher incidence of major complications after splenic embolization for blunt splenic injuries in elderly patients. Am J Emerg Med 2011;29:135-40.

60. Abbey-Mensah G, Herskowitz MM, Walsh J, et al. Massive hematemesis from a splenic artery pseudoaneurysm presenting two years after penetrating trauma. Case Rep Radiol 2018;2018:7473168.

61. Loffroy R, Guiu B, Cercueil JP, et al. Transcatheter arterial embolization of splenic artery aneurysms and pseudoaneurysms: short- and long-term results. Ann Vasc Surg 2008;22:618-26.

62. Norotsky MC, Rogers FB, Shackford SR. Delayed presentation of splenic artery pseudoaneurysms following blunt abdominal trauma: case reports. J Trauma 1995;38:444-7.

63. Ruhnke H, Kröncke TJ. Visceral Artery Aneurysms and pseudoaneurysms: retrospective analysis of interventional endovascular therapy of 43 aneurysms. Rofo 2017;189:632-9.

64. Wong YC, Wu CH, Wang LJ, et al. Distal embolization versus combined embolization techniques for blunt splenic injuries: comparison of the efficacy and complications. Oncotarget 2017;8:95596-605.

65. Koconis KG, Singh H, Soares G. Partial splenic embolization in the treatment of patients with portal hypertension: a review of the English language literature. J Vasc Interv Radiol 2007;18:463-81.

66. Ekeh AP, Khalaf S, Ilyas S, et al. Complications arising from splenic artery embolization: a review of an 11-year experience. Am J Surg 2013;205:250-4; discussion 254.

67. Haan JM, Biffl W, Knudson MM, et al. Splenic embolization revisited: a multicenter review. J Trauma 2004;56:542-7.

68. Lopera JE. Embolization in trauma: principles and techniques. Semin Intervent Radiol 2010;27:14-28.

69. Dudeck O, Bulla K, Wieners G, et al. Embolization of the gastroduodenal artery before selective internal radiotherapy: a prospectively randomized trial comparing standard pushable coils with fibered interlock detachable coils. Cardiovasc Intervent Radiol 2011;34:74-80.

70. Park SI, Lee SJ, Lee M, et al. Prospective randomized trial comparing pushable coil and detachable coil during percutaneous implantation of port-catheter system for hepatic artery infusion chemotherapy. Abdom Imaging 2015;40:595-600.

71. Jambon E, Hocquelet A, Petitpierre F, et al. Proximal embolization of splenic artery in acute trauma:

Comparison between Penumbra occlusion device versus coils or Amplatzer vascular plug. Diagn Interv Imaging 2018;99:801-8.

72. Ng EH, Comin J, David E, et al. AMPLATZER Vascular Plug 4 for proximal splenic artery embolization in blunt trauma. J Vasc Interv Radiol 2012;23:976-9.

73. Wang W, Li H, Tam MD, et al. The amplatzer vascular plug: a review of the device and its clinical applications. Cardiovasc Intervent Radiol 2012;35:725-40.

74. Wang W, Tam MD, Spain J, et al. Gelfoam-assisted amplatzer vascular plug technique for rapid occlusion in proximal splenic artery embolization. AJR Am J Roentgenol 2013;200:677-81.

75. Widlus DM, Moeslein FM, Richard HM 3rd. Evaluation of the Amplatzer vascular plug for proximal splenic artery embolization. J Vasc Interv Radiol 2008;19:652-6.

76. Zhu X, Tam MD, Pierce G, et al. Utility of the Amplatzer Vascular Plug in splenic artery embolization: a comparison study with conventional coil technique. Cardiovasc Intervent Radiol 2011;34:522-31.

77. IMPEDE@ Embolization Plug. Lawrence Livermore National Laboratory. 2019. Available online: https://ipo. llnl.gov/content/assets/docs/award-archive/impede.pdf

78. Malhotra A, Gary S. The MVP' Microvascular Plug A valuable addition to the armamentarium for peripheral embolization. Endovascular Today 2016;15:75-8.

79. Corn S, Reyes J, Helmer SD, et al. Outcomes Following Blunt Traumatic Splenic Injury Treated with Conservative or Operative Management. Kans J Med 2019;12:83-8.

80. Frandon J, Rodiere M, Arvieux C, et al. Blunt splenic injury: outcomes of proximal versus distal and combined splenic artery embolization. Diagn Interv Imaging 
2014;95:825-31.

81. Banerjee A, Duane TM, Wilson SP, et al. Trauma center variation in splenic artery embolization and spleen salvage: a multicenter analysis. J Trauma Acute Care Surg 2013;75:69-74; discussion 74-5.

82. Bessoud B, Duchosal MA, Siegrist CA, et al. Proximal splenic artery embolization for blunt splenic injury: clinical, immunologic, and ultrasound-Doppler follow-up. J Trauma 2007;62:1481-6.

83. Crichton JCI, Naidoo K, Yet B, et al. The role of splenic angioembolization as an adjunct to nonoperative management of blunt splenic injuries: A systematic review and meta-analysis. J Trauma Acute Care Surg 2017;83:934-43.

84. Frandon J, Rodiere M, Arvieux C, et al. Blunt splenic injury: are early adverse events related to trauma, nonoperative management, or surgery? Diagn Interv Radiol 2015;21:327-33.

85. Haan JM, Bochicchio GV, Kramer N, et al. Nonoperative management of blunt splenic injury: a 5-year experience. J Trauma 2005;58:492-8.

86. Mebert RV, Schnuriger B, Candinas D, et al. Follow-Up Imaging in Patients with Blunt Splenic or Hepatic Injury Managed Nonoperatively. Am Surg 2018;84:208-14.

87. Requarth JA, D'Agostino RB Jr, Miller PR. Nonoperative management of adult blunt splenic injury with and without splenic artery embolotherapy: a meta-analysis. J Trauma 2011;71:898-903; discussion 903.

88. Olthof DC, Lammers AJ, van Leeuwen EM, et al. Antibody response to a $\mathrm{T}$-cell-independent antigen is preserved after splenic artery embolization for trauma. Clin Vaccine Immunol 2014;21:1500-4.

89. Killeen KL, Shanmuganathan K, Boyd-Kranis R, et al. CT findings after embolization for blunt splenic trauma. J Vasc Interv Radiol 2001;12:209-14.

90. Haan J, Bochicchio G, Kramer M, et al. Air following

Cite this article as: Cretcher M, Panick CEP, Boscanin A, Farsad K. Splenic trauma: endovascular treatment approach. Ann Transl Med 2021;9(14):1194. doi: 10.21037/atm-20-4381 splenic embolization: infection or incidental finding? Am Surg 2003;69:1036-9; discussion 1039-40.

91. Cioci AC, Parreco JP, Lindenmaier LB, et al. Readmission for infection after blunt splenic injury: A national comparison of management techniques. J Trauma Acute Care Surg 2020;88:390-5.

92. Skattum J, Loekke RJ, Titze TL, et al. Preserved function after angioembolisation of splenic injury in children and adolescents: a case control study. Injury 2014;45:156-9.

93. de Porto APNA, Lammers AJJ, Bennink RJ, et al. Assessment of splenic function. Eur J Clin Microbiol Infect Dis 2010;29:1465-73.

94. Schimmer JA, van der Steeg AF, Zuidema WP. Splenic function after angioembolization for splenic trauma in children and adults: A systematic review. Injury 2016;47:525-30.

95. Malhotra AK, Carter RF, Lebman DA, et al. Preservation of splenic immunocompetence after splenic artery angioembolization for blunt splenic injury. J Trauma 2010;69:1126-30; discussion 1130-1.

96. Crooker KG, Howard JM, Alvarado AR, et al. Splenic Embolization After Trauma: An Opportunity to Improve Best Immunization Practices. J Surg Res 2018;232:293-7.

97. Leeper WR, Leeper TJ, Ouellette D, et al. Delayed hemorrhagic complications in the nonoperative management of blunt splenic trauma: early screening leads to a decrease in failure rate. J Trauma Acute Care Surg 2014;76:1349-53.

98. Liechti R, Fourie L, Stickel M, et al. Routine followup imaging has limited advantage in the non-operative management of blunt splenic injury in adult patients. Injury 2020;51:863-70.

99. Zarzaur BL, Kozar R, Myers JG, et al. The splenic injury outcomes trial: An American Association for the Surgery of Trauma multi-institutional study. J Trauma Acute Care Surg 2015;79:335-42. 